\title{
NEW ERA IN POSTOPERATIVE ANALGESIA IN SPINAL SURGERY: THORACOLUMBAR INTERFASCIAL PLANE (TLIP) BLOCK
}

(1) Çağla Bali

\author{
Başkent University, Department of Anesthesiology and Reanimation, Adana, Turkey
}

Keywords: Analgesia, spinal surgery, tlip block

Dear Editor;

Spinal surgeries are painful procedures, and effective postoperative analgesia improves patient outcomes and reduces complications, thus reducing hospital stay and preventing the development of chronic pain ${ }^{(1)}$. For this purpose, neuraxial methods such as subarachnoid and epidural block, paravertebral block, systemic opioid infusion with a patientcontrolled analgesia device and wound infiltration techniques are applied in these surgeries.

Recently, with the widespread use of ultrasound in anesthesia practice, regional anesthesia has been performed very frequently both for anesthetic purposes and to provide postoperative analgesia. Thoracolumbar interfascial plane (TLIP) block, one of these applications, is a technique that was first defined in 2015 in single-level lumbar spinal surgery by injecting local anesthetic bilaterally into the fascial area between the multifidus and longissimus muscles at the L3 level. At this point, the target is the dorsal ramus of the thoracolumbar nerves. Patients described the loss of sensation starting from the midline at the injection level and spreading cephalolaterally at the $20^{\text {th }}$ minute ${ }^{(2)}$. Later, a modified technique, lateral TLIP, was defined, which is more comfortable for viewing, ease of application, and reduces the possibility of neuraxial puncture. In this technique, the block is performed between the iliocostal and longissimus muscles and has been shown to be as effective as classical TLIP(3). In another study, modified lateral TLIP was performed bilaterally from the $L 3$ vertebra level in a multilevel spinal surgery with a local anesthetic injection of $40 \mathrm{~mL}$ ( $20 \mathrm{~mL}$ on each side). It was reported that there was a sensory loss from the left midaxillary area to the right midaxillary area between L1-L5 segments, and the patients did not require additional analgesics ${ }^{(4)}$. In another lumbar spinal surgery study, it was mentioned that TLIP block suppresses the hemodynamic response to surgical stress and reduces intraoperative analgesic consumption ${ }^{(5)}$. In a case series in which awake endoscopic laminectomy with mild sedation was applied, it was stated that there was a loss of sensation between T12-L5 25 minutes after the block was performed, and the patients did not require analgesics during the surgery and for 24 hours postoperatively ${ }^{(6)}$.

Studies on TLIP are mostly case reports or randomized controlled studies completed with a small sample size, and they have not yet been studied in an important population such as pediatric scoliosis cases. With more randomized controlled studies, this easy-to-apply minimally invasive block may be an effective component of multimodal analgesia in the near future.

\section{Ethics}

Peer-review: Internally peer-reviewed.

Financial Disclosure: The author have no sources of support for this work.

\section{REFERENCES}

1. Joshi GP, Ogunnaike BO. Consequences of inadequate postoperative pain relief and chronic persistent postoperative pain. Anesthesiol Clin North Am. 2005;23:21-36.

2. Hand WR, Taylor JM, Harvey NR, Epperson TI, Gunselman RJ, Bolin ED, et al. Thoracolumbar interfascial plane (TLIP) block: a pilot study in volunteers. Can J Anaesth. 2015;62:1196-2000.

3. Ahiskalioglu A, Yayik AM, Doymus O, Selvitopi K, Oral Ahiskalioglu E, Calikoglu C, et al. Efficacy of ultrasound-guided modified thoracolumbar interfascial plane block for postoperative analgesia after spinal surgery: a randomized-controlled trial. Can J Anesth. 2018;65:603-4.

4. Li C, Jia J, Qin Z, Tang Z. The use of ultrasound-guided modified thoracolumbar interfascial plane (TLIP) block for multi-level lumbar spinal surgery. J Clin Anesth. 2018;46:49-51.

5. Eltaher E, Nasr N, Abuelnaga ME, Elgawish Y. Effect of ultrasoundguided thoracolumbar interfascial plane block on the analgesic 
requirements in patients undergoing lumbar spine surgery under general anesthesia: a randomized controlled trial. I Pain Res. 2021;14:3465-74.
6. Christopher S, Gopal T, Vardhan V. Thoracolumbar interfascial plane block, way forward for awake endoscopic laminectomies. Indian J Anaesth. 2020;64:436-7. 